\title{
Population Aging, Intergenerational Transfers, and the Macroeconomy
}

\author{
by R. Clark, N. Ogawa, and A. Mason (eds.) \\ Northampton, MA: Edward Elgar, 2007 \\ ISBN 978-1847200990 \\ US\$125.00, $318 \mathrm{pp}$.
}

\author{
Reviewed by Susan A. McDaniel \\ Prentice Research Chair in Global Population \& Economy \\ University of Lethbridge \\ susan.mcdaniel@uleth.ca
}

With the global economy suffering and informed analyses wanting, any book with the term macroeconomy in the title seems enticing. The back dustcover suggests that this volume will be of interest to "students and scholars of population economics, public sector economics, welfare economics, social economics and public finance," as well as pension analysts and government policymakers.

This edited volume, the proceedings of a 2006 international conference convened in Tokyo, is organized into three substantive sections, preceded by an introductory chapter: population aging and labor markets; savings and wealth; and policy. Chapters in the first section focus on retirement in Japan (by Clark, Ogawa, and Matsukura), productivity by age in Austria (by Prskawetz, Mahlberg, and Skirbekk), and survival probabilities and wealth in the US (by Bloom, Canning, Moore, and Song). The savings and wealth section has four chapters: on modelling aging and consumption (by Hock and Weil), transfers, capital, and consumption (by Mason and Lee), the effects of age on investment (by Lindh and Malmberg), and on population and healthcare spending in Japan (by Ogawa, Mason, Matsukura, and Nemoto). The last section, on policy, includes papers by de la Croix and Gosseries on tradable quotas, by Guest on Australia's Future Fund, and by Heller on whether Asia is prepared for an aging population.

The papers in this volume, as in many edited volumes, are uneven. Some offer interesting new findings to the educated researcher/reader. Among those is the study by Bloom et al., which follows a representative sample of Americans aged 51-61 from 1991 through 2004 from the Health and Retirement Survey. They find that greater subjective probabilities of survival contribute to increased household wealth accumulation. In contrast, institutional incentives effectively constrain retirement decisions, a finding that is consistent with previous research. The Bloom et al. study suggests that conveying accurate information on estimates of life horizons and health may have an impact on savings. These findings also suggest, provocatively in policy terms, that eliminating institutional arrangements of public pension provision could result in positive changes in both labour supply and savings. This is 
consistent with Esping-Andersen's recent analyses in other state contexts (Esping-Andersen 2009), but adds the novel determinant of subjective estimation of survival probabilities.

Another study presented here with interesting new findings is by Prskawetz and colleagues - testing, with Austrian matched employer-employee data, the presumption that an aging workforce is associated with lower productivity. They work to isolate the effect of employee age from other influences in the workplace. The Austrian dataset includes economic as well as socio-demographic numbers for each firm. The study finds, significantly, that the share of older workers is negatively associated with productivity only for small firms. Extending these findings beyond what the authors say, if it is the case that firm characteristics matter more than individual characteristics of employees, then policymakers might pay greater attention to the mix of small versus large firms in the economy, something seldom heard in relation to aging workforce.

A third study that offers interesting new findings is that by Ogawa et al. examining healthcare spending in Japan, and essentially how Japan, with the most demographically old population in the world, can maintain a relatively inexpensive healthcare system. The key to this conundrum, they find, is dual: Japan's stringent medical fee schedule and a series of age-based policies and programs, such as a cost-sharing scheme for the elderly. They also find that Japan's long-term care insurance program works to mitigate the effect of population aging on long-term medical expenses.

Several of the papers seem to have been on the drawing board longer than 2007. They review what is already known, although they do that well, and add little new to the knowledge base. This is clearly an economics book, which may or may not be clear to readers from the title. It focuses first and foremost on the economics of aging, relying on economic analytical approaches, sometimes to the neglect of the vast and growing demographic and sociological research on aging. This seems particularly the case in the Heller paper on aging in Asia, and in the Mason and Lee paper on transfers, capital, and consumption. But it is also true in the modelling exercises, of which economists are fond, by Hock and Weil, and to some extent in the papers by Lindh and Malmberg on the effects of age composition on capital flows, as well as those by de la Croix and Gosseries on tradable quotas, and by Guest on Australia's Future Fund.

With its attention to the minutiae of analysis and modelling, this is a book difficult to classify in terms of audience. It is not for the general audience or for early-year undergraduates, even in population economics. Perhaps it could usefully join other books on aging and the economy on the shelves of established researchers or graduate students. Of those listed on the dust-jacket as potential readers, public sector economists could have trouble with accessibility, as could pension analysts and government policymakers. There is something here for all of these audiences, but it is buried in quantities of detail, with implications for application or for policy insufficiently spelt out.

The first 22 pages of the book, including the title page, table of contents and list of contributors, have blurred, double print, making reading very challenging. This is unusually sloppy production for a serious publisher. One can only hope that the particular book I read was first off the production line, and other copies do not suffer from this production problem.

\section{References}

Esping-Andersen, G. 2009. The Incomplete Revolution: Adapting to Women's New Roles. Cambridge (UK): Polity. 